\title{
Effect of total occlusal convergence on fit and fracture resistance of zirconia-reinforced lithium silicate crowns
}

This article was published in the following Dove Medical Press journal: Clinical, Cosmetic and Investigational Dentistry

\author{
Manal Rahma Alammari' \\ Mohamed Hussein \\ Abdelnabi ${ }^{1,2}$ \\ Amal Ali Swelem ${ }^{1,3}$ \\ 'Oral and Maxillofacial Prosthodontic \\ Department, Faculty of Dentistry, \\ King Abdulaziz University, Jeddah, \\ Kingdom of Saudi Arabia; ${ }^{2}$ Removable \\ Prosthodontic Department, Faculty \\ of Dentistry, Minia University, Minia, \\ Egypt; ${ }^{3}$ Removable Prosthodontic \\ Department, Faculty of Dentistry, \\ Cairo University, Giza, Egypt
}

Introduction: Computer-aided design (CAD) and computer-aided manufacturing (CAM) monolithic crowns are gaining momentum. Limited evidence exists about the effect of tooth preparation total occlusal convergence (TOC) on marginal and internal gap distances in addition to load to fracture values.

Aim: The aim of this study was to evaluate, by microcomputed tomography $(\mu \mathrm{CT})$, the influence of $12^{\circ}$ and $20^{\circ} \mathrm{TOC}$ on marginal and internal adaptation of zirconia-reinforced lithium silicate (ZLS) crowns. Moreover, values of load to fracture with and without initial cyclic loading (CL) were compared.

Material and methods: Forty ZLS crowns were fabricated on dies with TOC of $12^{\circ}$ and $20^{\circ}$, 20 crowns for each group. $\mu \mathrm{CT}$ was used to compare marginal and internal adaptation. Each specimen was measured at 140 points distributed on all tooth preparation surfaces for 2D gap distance assessment. 3D gap volume was also evaluated. Crowns were then cemented and divided into two subgroups; the first was stored in distilled water (no cyclic loading [NCL] subgroup), the second was subjected to CL (CL subgroup).

Results: Factorial repeated measures ANOVA followed by Bonferroni post hoc in addition to independent and dependent $t$-tests were used for statistical analysis. Marginal gap, absolute marginal discrepancy, and occlusal gap measurements showed significant differences between the measurement sites. Static load to fracture values showed significant differences between TOC groups for both NCL $(P=0.011)$ and CL $(P=0.025)$ subgroups.

Conclusion: An increase of TOC from $12^{\circ}$ to $20^{\circ}$ did not affect marginal and internal adaptation but resulted in higher values of load to fracture of ZLS crowns. CL simulating 1 year of service did not result in fatigue failure.

Keywords: CAD, CAM, monolithic crowns, total occlusal convergence, $\mu \mathrm{CT}$, marginal gap

\section{Introduction}

The convenience of computer-aided design (CAD) and computer-aided manufacturing (CAM) has resulted in increased demand for monolithic restoration materials. ${ }^{1} \mathrm{CAD} /$ CAM fabricated monolithic ceramic crowns in contrast to traditional slip casting and hot pressing have a more homogenous structure. Crowns are milled from standardized fabricated blocks with minimal imperfections. ${ }^{2}$

Ceramic crowns are characterized by natural appearance and biocompatibility. ${ }^{3}$ The success of ceramic crowns is greatly determined by marginal and internal adaptation, resistance to fracture, and esthetic value. ${ }^{4,5}$ Inadequate fit and marginal discrepancies lead to the accumulation of dental biofilm, ${ }^{6}$ alteration of microflora distribution, ${ }^{6}$ increased caries risk, ${ }^{7}$ microleakage, ${ }^{8}$ periodontal diseases especially with subgingival margins, ${ }^{5}$ and excessive exposure of the cement to oral environment. ${ }^{9}$ Values of 
marginal gap (MG) reported in the dental literature range from $3.7 \mu \mathrm{m}$ to $200 \mu \mathrm{m} .^{4,10-14}$ The maximum acceptable MG is considered to be $120 \mu \mathrm{m} .{ }^{12}$

Techniques such as direct microscopy, ${ }^{15}$ impression replica technique, ${ }^{16}$ profilometry, ${ }^{17}$ and microcomputed tomography $(\mu \mathrm{CT})^{18,19}$ have been implemented to assess marginal and internal adaptation. $\mu \mathrm{CT}$ in comparison to the other techniques has the advantage of being non-destructive, delivers $2 \mathrm{D}$ and $3 \mathrm{D}$ reconstructions, and provides close sections with a great number of measurement points. ${ }^{17-19}$ Such features are not possible with the other techniques.

When lithium disilicate is used for crowns, there is no need for any metal or zirconia framework, ${ }^{2}$ therefore, chipping problems could be reduced. Lithium disilicate ceramic can be pressed or milled in CAD/CAM systems and has been successfully tested in clinical trials. ${ }^{2}$ Its flexural strength and fracture toughness are higher than that of conventional silicate ceramics. ${ }^{20-22}$ In an attempt to further improve durability, zirconia-reinforced lithium silicate (ZLS) glass ceramics has been introduced. ${ }^{23}$ ZLS ceramic contains lithium silicate crystals with an average size of $0.5 \mu \mathrm{m}$ with a synthetic glassy matrix and $8 \%-12 \%$ highly dispersed zirconia crystals. ${ }^{23,24}$ Zirconia is characterized by the phase transformation of its tetragonal to monoclinic phase. This transformation results in volume increase that inhibits crack propagation and increases the fracture strength. ${ }^{25,26}$ The excellent optical properties are still retained..$^{21}$

One of the critical parameters for success of ceramic crowns is the tooth preparation. Total occlusal convergence (TOC), which is the convergence angle between two opposing axial surfaces, was one of the first aspects to receive numeric recommendations, and the stability of the restoration is determined by the relationship of TOC, abutment height, and abutment diameter. ${ }^{13,27-33}$ Low values of TOC, which range from $2^{\circ}$ to $5^{\circ}$, are unrealistic and difficult to clinically achieve, and could also result in an increase in cement hydraulic pressure that negatively impacts the discharge of the excess cement. ${ }^{34-37} \mathrm{~A}$ number of studies assessed the effect of TOC on MG. ${ }^{35,38-42}$ In some of these studies, TOC had no impact on $\mathrm{MG} .^{39-42}$

Fracture resistance and resistance to fatigue failure under intraoral forces are important prerequisites for a successful restoration. ${ }^{46-50}$ Tooth preparation TOC also influences the amount of ceramic material used to achieve acceptable contours. The amount of ceramic has an impact on the mechanical properties including the fracture resistance of the restoration. ${ }^{32,47-49}$
The aim of this study was to investigate the influence of tooth preparation TOC for ZLS crowns fabricated with a $\mathrm{CAD} / \mathrm{CAM}$ system on: 1) the marginal and internal adaptation; 2) cyclic fatigue; and 3) fracture load.

The null hypotheses were thus that the two different tooth preparation TOCs of $12^{\circ}$ and $10^{\circ}$ for ZLS crowns fabricated with a CAD/CAM system will not influence: first, the marginal and internal adaptation; second, the cyclic fatigue strength; and third, the fracture load.

\section{Materials and methods}

Two groups of ZLS crowns were fabricated. The first group was with a TOC of $12^{\circ}$ while the second had a TOC of $20^{\circ}$. Each group included 20 crowns. $\mu \mathrm{CT}$ was used to compare marginal and internal adaptation of the two groups. The crowns were then cemented to their respective dies and subjected to cyclic loading $(\mathrm{CL})$ followed by load to fracture tests.

A complete coverage preparation for a ZLS crown (Vita Suprinity, Vita Zahnfabrik, Bad Säckingen, Germany) was prepared on two typodont right mandibular molars (Standard model ANA-4; Frasaco Franz Sachs, Tettnang, Germany) by a single operator (MRA). A milling machine (Paraskop M, Model no 26060; Bego, Bremen, Germany) was used to standardize the preparation. A medium grit, diamond rotary instrument was used to prepare a 1.2 circumferential rounded shoulder finish line. The preparation depth was $2 \mathrm{~mm}$ on the functional cusp and $1.5 \mathrm{~mm}$ on the non-functional cusp. One of the two typodont teeth was reduced axially to form a TOC of $12^{\circ}$ and the second a TOC of $20^{\circ}$.

The prepared typodont teeth were digitized with a laboratory scanner (ARCTICA AutoScan; KaVo Dental GmbH, Biberach, Germany) and the reference models were converted to standard triangulated language (STL) file format. Twenty duplicate dies for each group were produced from polymethyl methacrylate resin blocks (TempPremium A1-B1 95H16; Zirkonzahn) with a CAD/CAM milling unit (Everest CAD/ CAM System; KaVo). Replica dies were then scanned and each served as an individual master die. Individual data sets for each specimen were generated in STL format and then used on the milling machine.

All 40 crowns were designed with MultiCAD Software (KaVo). The crown margins were marked manually on the finish line of the preparation. The vertical and horizontal gaps were set at $40 \mu \mathrm{m}$ with a $1.2 \mathrm{~mm}$ marginal ramp. ZLS blocks were milled using a 5 -axis milling machine. Burs were changed every 20 specimens. Crown margins were examined under the microscope $(\times 10)$. No adjustments of the crown 
inner surface were carried out. Crowns were then positioned in a porcelain furnace (Programat CS2, Ivoclar Vivadent, Schaan, Liechtenstein, Liechtenstein) with a firing paste (Vita; Vita Zahnfabrik) for the crystallization phase. Crown margins were then reassessed under the microscope $(\times 10)$.

An index was used to stabilize and position each surface of the master dies (buccal, lingual, mesial, and distal). The obtained four silicone indices were then attached to the manual milling machine. Four standardized reference indentations were then prepared below the finish line for all the dies on the buccal, lingual, mesial, and distal surfaces. These indentations were then used to standardize $\mu \mathrm{CT}$ image assessment.

Marginal and internal adaptations were analyzed by highresolution $\mu \mathrm{CT}$ images (SkyScan 1172; Bruker, Kontich, Belgium). Each crown was stabilized in the scanning tube on its respective die before scanning and being positioned perpendicular to the scanning X-ray beam. The X-ray tube operated at $100 \mathrm{kV}, 100 \mathrm{~mA}$, using Al Cu filter. The image pixel size was $10 \mu \mathrm{m}$, and the scanning time was approximately $60 \pm 1$ minutes for each specimen.

The acquired projection images were reconstructed in crosssection slices. Data viewer program was used to analyze the scans and section the 3D models. The software (CT-analyzer; Bruker micro-CT) was then used to obtain five vertical buccolingual sections with 50 equidistant slice intervals and five vertical mesiodistal sections with 30 equidistant slice intervals.

The following measuring locations were used for $2 \mathrm{D}$ adaptation assessment: $\mathrm{MG}$, absolute marginal discrepancy (AMD), axial gap (AG), and occlusal gap (OG) ${ }^{14}$ (Figures 1 and 2). Each specimen had a total of 140 measurements (14 points/section and a total of ten sections). Additionally, $3 \mathrm{D}$ qualitative evaluation and visualization were carried out.

Crowns were then cemented to their respective dies. Crowns were cleaned with ethyl alcohol in an ultrasonic bath and air dried. Five percentage hydrofluoric acid gel (Ivoclar

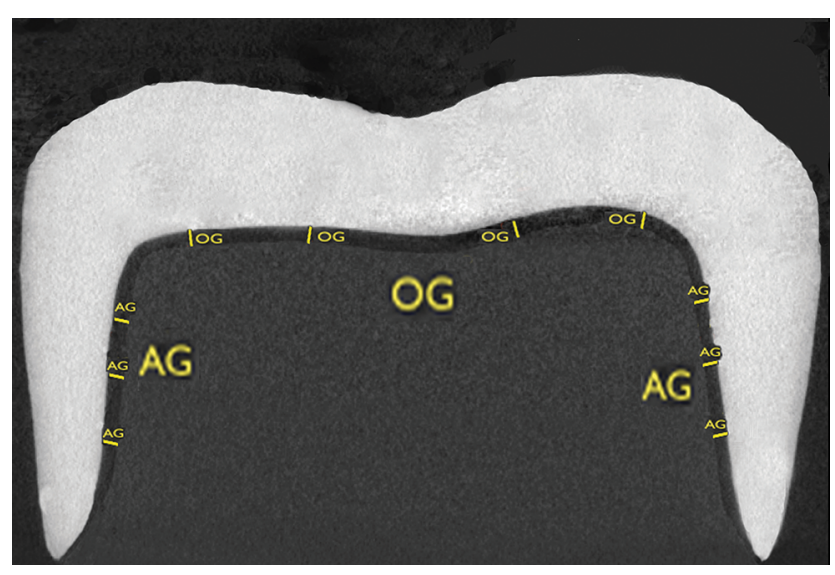

Figure I 2D adaptation assessment: axial gap (AG) and occlusal gap (OG).
Vivadent AG) was applied to the inner surface of the crowns for 20 seconds, they were rinsed in water and air dried. Silane coupling agent (Monobond Plus; Ivoclar Vivadent AG) was applied for 60 seconds to the inside of the crowns. Multilink Automix Primer (Ivoclar Vivadent AG) was applied on the dies. Multilink Automix (Ivoclar Vivadent AG) was used to lute the crowns under a load of 10 N. After photopolymerization of the cement, the excess was chipped away and stored in distilled water for 24 hours at $37^{\circ} \mathrm{C}$.

Dies with the cemented crowns were vertically positioned in resin blocks. Each group was then divided into two subgroups (ten crowns/subgroup). The first subgroup (no CL) was left in distilled water at $37^{\circ} \mathrm{C}$, while the second subgroup (CL) was subjected to CL.

Specimens of the CL subgroup were then held with their bases in a dynamic loading machine (Instron Dynamic testing machine) in $37^{\circ} \mathrm{C}$ distilled water (Figure 3 ). The specimens were subjected to $10^{6}$ cycles at $4 \mathrm{~Hz}$ and a load of $88 \mathrm{~N}$ of cyclic fatigue to simulate a year of oral service. The specimens were then inspected for features of surface

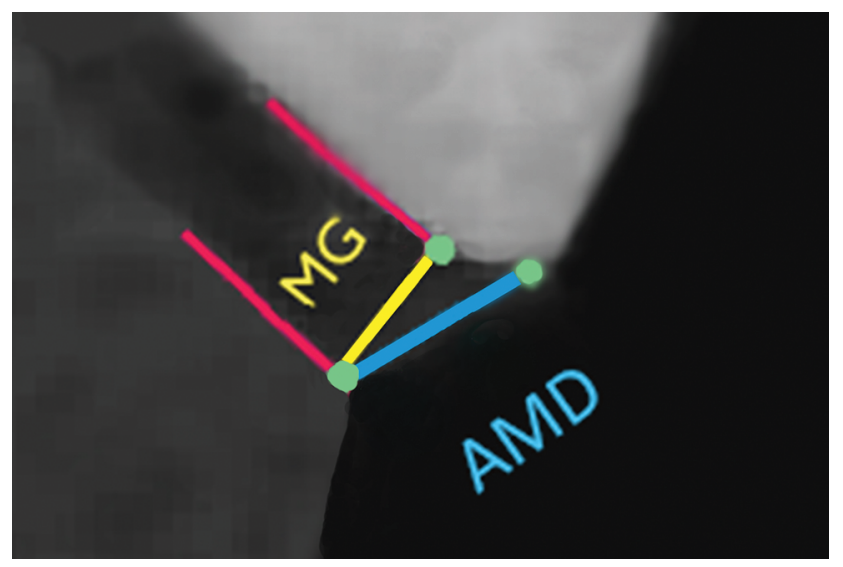

Figure 2 2D adaptation assessment: marginal gap (MG), absolute marginal discrepancy (AMD).

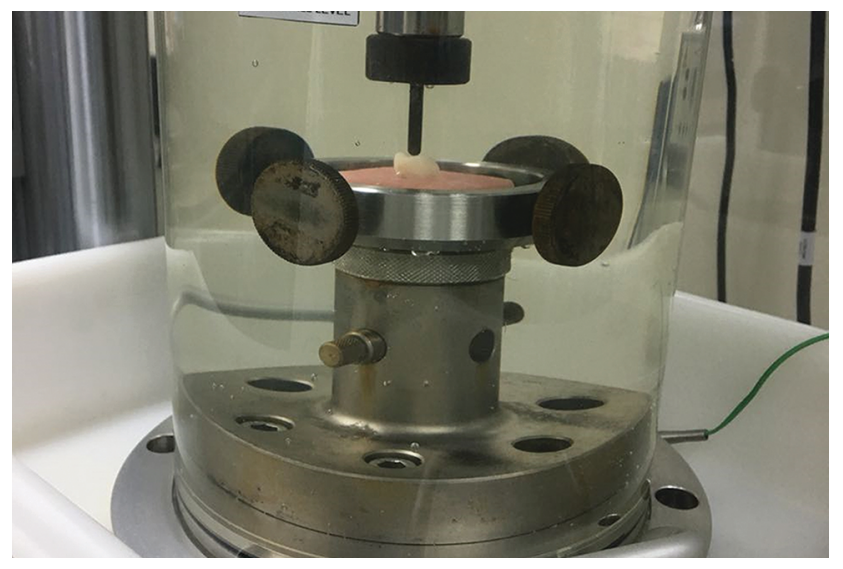

Figure 3 Specimens of the cyclic loading subgroup were held with their bases in a dynamic loading machine (Instron dynamic testing machine). 
damage under the stereomicroscope. None of the specimens showed any features of damage.

All 40 specimens were then placed in a universal testing machine (Instron universal testing machine) and submitted to compressive load test (crunch the crown test) at a cross head speed of $0.5 \mathrm{~mm} / \mathrm{min}$. Load (in Newtons) to fracture was registered (Figure 4).

Power calculation software (G Power 3.1.3) was used to calculate the sample size at an estimated power of $>90 \%$. The estimated sample size for each gap distance group was 12 and 8 for each fracture strength subgroup. ${ }^{32,38}$ The actual sample size in this study was a total of 40 crowns divided into two groups used to compare gap distances. For fracture strength, each group was further subdivided into two subgroups of ten each. These sample sizes were thus larger than those estimated by the power calculation analysis.

Statistical analysis was carried out by using statistical software (SPSS v17.00; SPSS Inc., Chicago, IL, USA). Distribution of data for all variables was assessed by the Kolmogorov-Smirnov test. Normal distribution and homogeneity were verified. Mean values and SDs were calculated

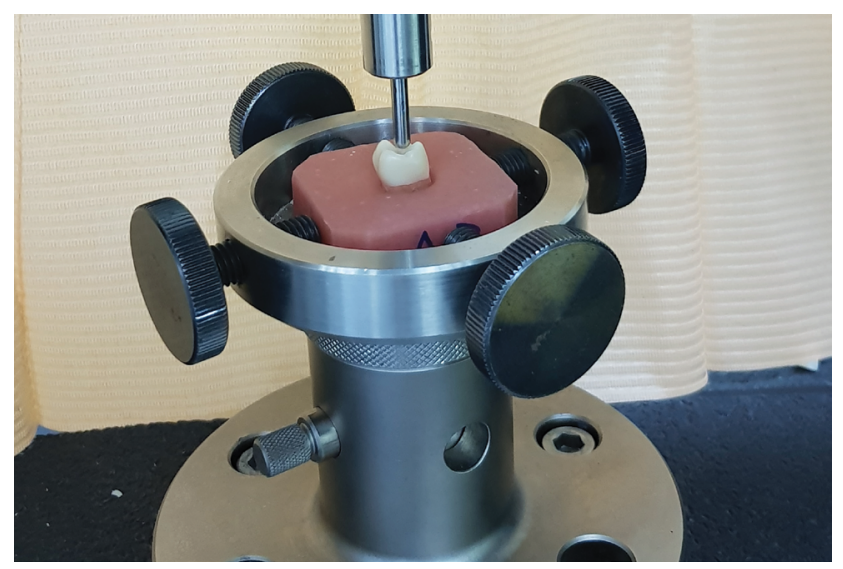

Figure 4 Specimen placed in a universal testing machine (Instron universal testing machine) and submitted to compressive load test (crunch the crown test) at a cross head speed of $0.5 \mathrm{~mm} / \mathrm{min}$. and analyzed. Factorial repeated measures ANOVA followed by Bonferroni post hoc tests were used to compare 2D of all gap distance measurements except OG. Effects of group, site of measurement, and their interaction were analyzed. Independent $t$-test was further used for between-group comparisons for 2D, 3D, and load to fracture tests. Dependent $t$-test was used to compare the effect of CL within each group in addition to effect of site for OG points. For all statistical analyses $\alpha=0.05$.

\section{Results}

A total of 400 reconstructed images of $\mu \mathrm{CT}$ images were evaluated for all 40 crowns. The total number of points for $2 \mathrm{D}$ assessment were 5,600 $(\mathrm{MG}=800, \mathrm{AMD}=800, \mathrm{AG}$ $=2,400, \mathrm{OG}=1,600)$.

Results of the factorial repeated measures ANOVA followed by Bonferroni post hoc test for the points MG, AMD, and AG are shown in Table 1. Results revealed insignificant effect of TOC difference (MG: $P=0.128$, AMD: $P=0.181$, AG: $P=0.205)$. Buccal site gaps for $M G$ and AMD points were significantly higher than the other sites in both groups $(P<0.001)$. Differences between AG sites were insignificant (AG: $P=0.187$ ). There were no interactions between group and site (MG: $P=0.959$, AMD: $P=0.723, \mathrm{AG}: P=0.943$ ). Independent $t$-tests between groups for $\mathrm{MG}, \mathrm{AMD}$, and $\mathrm{AG}$ at each site of measurement were statistically insignificant (Table 1).

Independent $t$-test results for OG showed an insignificant difference between TOC groups for both sites. Differences between sites analyzed by dependent $t$-test were significant (Table 2). Similarly, 3D gap space measurements showed insignificant differences between groups when compared with dependent $t$-test (Table 3 ).

Independent $t$-test of fracture strength revealed significant differences between TOC groups. The effect of CL in both groups assessed by dependent $t$-test was insignificant (Table 4).

Table I Mean values ( $\mu \mathrm{m})$ of MG, AMD, and AG for test groups

\begin{tabular}{|c|c|c|c|c|c|c|c|c|c|}
\hline \multirow[t]{2}{*}{ Variables } & \multicolumn{3}{|c|}{ Mean values $(\mu \mathrm{m})$ of MG } & \multicolumn{3}{|c|}{ Mean values $(\mu \mathrm{m})$ of AMD } & \multicolumn{3}{|c|}{ Mean values $(\mu \mathrm{m})$ of AG } \\
\hline & $12^{\circ} \mathrm{TOC}$ & $20^{\circ} \mathrm{TOC}$ & $\boldsymbol{P}$ & $12^{\circ} \mathrm{TOC}$ & $20^{\circ} \mathrm{TOC}$ & $\boldsymbol{P}$ & $12^{\circ} \mathrm{TOC}$ & $20^{\circ} \mathrm{TOC}$ & $P$ \\
\hline $\begin{array}{l}\text { Mesial } \\
\text { Mean } \pm \text { SD }\end{array}$ & $52.96 \pm 18.26^{a}$ & $50.50 \pm 16.73^{a}$ & 0.322 & $86.08 \pm 30.00^{a}$ & $86.12 \pm 28.59^{a, b}$ & 0.992 & $66.13 \pm 27.44$ & $65.13 \pm 30.26$ & 0.673 \\
\hline $\begin{array}{l}\text { Distal } \\
\text { Mean } \pm \text { SD }\end{array}$ & $50.09 \pm 16.04^{a}$ & $49.15 \pm 16.94^{\mathrm{a}}$ & 0.687 & $82.15 \pm 31.05^{a}$ & $80.61 \pm 27.40^{\mathrm{a}}$ & 0.710 & $63.36 \pm 25.68$ & $62.47 \pm 25.63$ & 0.671 \\
\hline $\begin{array}{l}\text { Buccal } \\
\text { Mean } \pm \text { SD }\end{array}$ & $63.15 \pm 24.17^{b}$ & $60.29 \pm 21.46^{\mathrm{b}}$ & 0.377 & $103.39 \pm 33.97^{\mathrm{b}}$ & $95.93 \pm 33.40^{\mathrm{b}}$ & 0.119 & $66.23 \pm 25.60$ & $63.75 \pm 24.76$ & 0.229 \\
\hline $\begin{array}{l}\text { Lingual } \\
\text { Mean } \pm \text { SD }\end{array}$ & $53.54 \pm 18.67^{a}$ & $51.75 \pm 17.88^{\mathrm{a}}$ & 0.490 & $85.39 \pm 32.91^{\mathrm{a}}$ & $82.47 \pm 30.14^{\mathrm{a}}$ & 0.514 & $62.49 \pm 24.77$ & $61.40 \pm 22.97$ & 0.575 \\
\hline$P$ & $<0.001$ & $<0.001$ & & $<0.001$ & $<0.001$ & & 0.184 & 0.371 & \\
\hline
\end{tabular}

Note: Mean values followed by different letters in same column show statistical difference $(P<0.05)$.

Abbreviations: MG, marginal gap; AMD, absolute marginal discrepancy; AG, axial gap; TOC, total occlusal convergence. 
Table 2 Mean values $(\mu \mathrm{m})$ of OG for test groups

\begin{tabular}{|l|l|l|l|}
\hline Groups & $\begin{array}{l}\text { Mean } \pm \text { SD } \\
\text { mesiodistal }\end{array}$ & $\begin{array}{l}\text { Mean } \pm \text { SD } \\
\text { buccolingual }\end{array}$ & $P$ \\
\hline $\mathbf{I} 2^{\circ}$ TOC & $117.96 \pm 42.9 I$ & $105.34 \pm 38.5 I$ & $<0.00 I$ \\
$20^{\circ}$ TOC & $114.15 \pm 40.30$ & $102.73 \pm 36.7 \mid$ & $<0.001$ \\
$P$ & 0.196 & 0.327 & \\
\hline
\end{tabular}

Note: $P<0.05$.

Abbreviations: OG, occlusal gap; TOC, total occlusal convergence.

Table 3 Mean values $\left(\mathrm{mm}^{3}\right)$ of cement space for test groups

\begin{tabular}{|l|l|}
\hline Groups & Mean \pm SD \\
\hline $12^{\circ}$ TOC & $17.17 \pm 6.29$ \\
$20^{\circ}$ TOC & $17.87 \pm 4.39$ \\
$P$ & 0.685 \\
\hline
\end{tabular}

Note: $P<0.05$.

Abbreviation: TOC, total occlusal convergence.

Table 4 Mean values $(\mathrm{N})$ of fracture strength for test groups

\begin{tabular}{|l|l|l|l|}
\hline Groups & $\begin{array}{l}\text { Fracture strength - } \\
\text { NCL subgroup } \\
\text { (mean } \pm \text { SD) }\end{array}$ & $\begin{array}{l}\text { Fracture strength - } \\
\text { CL subgroup } \\
\text { (mean } \pm \text { SD) }\end{array}$ & $P$ \\
\hline $\mathbf{I 2}^{\circ}$ TOC & $2004 \pm 194$ & $2070 \pm 241$ & 0.532 \\
$\mathbf{2 0}^{\circ}$ TOC & $2247 \pm 190$ & $2326 \pm 224$ & 0.297 \\
$\boldsymbol{P}$ & 0.011 & 0.025 & \\
\hline
\end{tabular}

Note: $P<0.05$.

Abbreviations: N, Newton; TOC, total occlusal convergence; NCL, no cyclic loading; $\mathrm{CL}$, cyclic loading.

\section{Discussion}

The first and second null hypotheses were accepted, namely that the TOC will neither affect the internal and marginal adaptation nor influence the fatigue strength of ZLS crowns. On the other hand, the third null hypothesis that the TOC will not affect the fracture strength was rejected.

Reviewing the dental literature revealed the limited number of studies assessing ZLS crowns. Increased gap distance and fracture strength are among the potential causes of failure of dental ceramics. The gap distance was assessed prior to cementation to eliminate the influence of the luting cement as a variable. ${ }^{36}$ Rounded shoulder finish line was used as it seems to result in the best adaptation..$^{50}$ In some $\mu \mathrm{CT}$ cuts, the buccal MG and AMD values were greater than the other sites. This could be attributed to the finish line curvature which was relatively pronounced on the buccal surface of the first mandibular molar typodont tooth used in the study at hand.$^{38} \mathrm{In}$ this in vitro study, the tooth preparation was carried out in accordance with the clinical recommendations. The finish line curvature was prepared to simulate the presence of gingival margin and the occlusal reduction to follow the occlusal anatomy. These conditions were considered to be more realistic in comparison to studies that used metallic models with simplified margins and occlusal surfaces. ${ }^{50}$

Studies have reported values of MG between 50 and 200 $\mu \mathrm{m}$ as acceptable. ${ }^{51}$ Boitelle et al ${ }^{10}$ in a systematic review, reported that $\mathrm{CAD} / \mathrm{CAM}$ technology can achieve an MG of less than $80 \mu \mathrm{m}$ and that both digital and conventional impressions presented similar MG values. Papadiochou et $a 1,{ }^{11}$ in a systematic review, concluded that the performance of CAD/CAM systems relative to MG is influenced by the restorative material. Gardner ${ }^{4}$ reported that the ideal marginal fit of $25-40 \mu \mathrm{m}$, even under ideal conditions, was very rarely achieved. McLean and von Fraunhofer ${ }^{12}$ carried out a 5-year study and concluded that for more than 1,000 restorations, $120 \mu \mathrm{m}$ was the maximum acceptable MG. Contrepois et al, ${ }^{13}$ in a systematic review, reported that $94.9 \%$ of the values of MG retrieved from their review measured less than $120 \mu \mathrm{m}$. The widest MG was $174 \mu \mathrm{m}$, and the smallest was $3.7 \mu \mathrm{m}$. Values of marginal and internal adaptation in the current study are comparable to those reported by Yildrim et $\mathrm{al}^{14}$ for ZLS crowns. It is worth mentioning that the MG measured in the present study did not exceed $120 \mu \mathrm{m}$ in both groups, which is clinically acceptable.

The differences between the marginal and internal adaptations between the two preparation angulations were statistically insignificant. The term preparation angulation in the literature refers to both the taper that is the inclination of the axial wall of the preparation in relation to the long axis of the tooth and to the TOC, which refers to an imaginary angle between the opposing prepared axial walls. TOC is thus double the angle of taper. ${ }^{13}$ A number of studies assessed the effect of the angle of preparation on the marginal fit of $\mathrm{CAD} / \mathrm{CAM}$ systems, some before and others after cementation. ${ }^{35,38-42}$ Most of these studies reported that angulation did not influence marginal fit. ${ }^{39-42}$ It is noteworthy that in one study conducted on cemented restorations, low preparation angulation hindered full seating because of increased cement hydraulic pressure. ${ }^{35}$ Despite the increased retention reported with decreased TOC, there are limitations related to frictional resistance and restoration strength. ${ }^{32}$ Some authors recommended that a TOC of $4^{\circ}$ to $10^{\circ}$ is ideal from the point of view of retention. ${ }^{52}$ Parallel preparations are also difficult to perform. These values seem, however, to be unrealistic in the clinical setting. ${ }^{28,31,34}$ Tiu et al, ${ }^{33}$ in a systematic review, reported that the achievable TOC ranges between $10^{\circ}$ and $20^{\circ}$. Studies reported TOC values between $4.1^{\circ 30}$ and $27.4^{027}$ with the tendency being rather toward higher TOC even when attempting to achieve a TOC of $6^{\circ}$. Beuer et a $\mathrm{l}^{35,41}$ considered $12^{\circ} \mathrm{TOC}$ to be ideal for $\mathrm{CAD} / \mathrm{CAM}$ metal-free crowns, which 
is still clinically difficult to achieve especially on the posterior teeth. ${ }^{27}$ Contrepois et al, ${ }^{13}$ in a systematic review, reported that a TOC between $10^{\circ}$ and $22^{\circ}$ seems acceptable, and Goodacre $^{29}$ was slightly more conservative and recommended a TOC between $10^{\circ}$ and $20^{\circ}$. It seems that the recommendation of Shillinburg et $\mathrm{al}^{34}$ is realistic, suggesting a TOC of up to $24^{\circ}$ mesiodistally and $20^{\circ}$ buccolingually, thus an average of $22^{\circ}$ for the mandibular first molars.

ZLS seems to be an attractive monolithic material with a flexural strength of $445 \mathrm{MPa}$ that is higher than that of lithium disilicate (362 MPa) and of conventional silicate ceramics (134 MPa). ZLS fracture toughness is $2.31 \mathrm{MPa} \mathrm{m}^{-0.5}$ which is higher than that of lithium disilicate $\left(2.0 \mathrm{MPa} \mathrm{m}^{-0.5}\right)$ and of conventional silicate ceramics $\left(1.74 \mathrm{MPa} \mathrm{m}^{-0.5}\right) .{ }^{20-22}$

It was attempted to create conditions similar to the oral environment for CL. The parameters of CL were adjusted to values reported in the literature. ${ }^{22}$ Fatigue failure is the cumulative damage caused by CL that results in slow crack propagation and ends in catastrophic failure under loading below the strength of a specific material. ${ }^{26,43}$ None of the specimens were affected by CL. Similar results were reported by Sieper et al, ${ }^{26}$ as all crowns in their study survived 1,200,000 cycles in a chewing simulator of $5 \mathrm{~kg}$ magnitude and with thermal cycling. In both the study at hand and that of Sieper et al, ${ }^{26}$ the ceramic crowns were etched and bonded to the underlying structure. The strengthening effect of the adhesive cementation might have contributed to the favorable outcomes. ${ }^{46}$ Preis et $\mathrm{al}^{45}$ compared the fracture resistance of conventionally cemented, self adhesively cemented, and adhesively bonded ZLS crowns subjected to combined thermal cycling and mechanical loading. Tendency for the highest values were for adhesive bonding but with no statistical significance.

Static load to fracture test that was carried out on all specimens showed a significant increase in fracture strength with an increase in TOC. A similar finding was reported by Corazza et al, ${ }^{32}$ who compared the influence of $6^{\circ}, 12^{\circ}$, and $20^{\circ}$ TOC on the fracture load of yttria partially stabilized zirconia veneered with feldspathic porcelain. The $20^{\circ} \mathrm{TOC}$ had the best performance. The greater fracture strength with the higher TOC has been attributed to the greater material bulk. ${ }^{38}$ Other studies have similarly reported that increased amount of ceramic improves the mechanical properties, including fracture resistance. ${ }^{47-49}$

It is worth mentioning that in both groups irrespective of TOC, the values of fracture strength were higher than the magnitude of intra-oral forces. Waltimo and Könönen ${ }^{44}$ reported maximum bite force in the molar region of $847 \mathrm{~N}$ and $597 \mathrm{~N}$ for males and females respectively. In the present study, the load to fracture mean values ranged from 2,004 N to 2,315 N, which is greater than the maximum bite forces. The values recorded in this study are comparable to those reported in the literature, which reported a fracture resistance of more than 2,200 $\mathrm{N}$ for $1 \mathrm{~mm}$ occlusal thickness. ${ }^{21,23,26,46}$

The initial dynamic loading had no influence on the fracture strength of the tested specimens under static load, as there were no significant differences in load to fracture values between the subgroups that were subjected to CL in comparison to the other subgroups that were only stored in distilled water irrespective of the TOC. This finding is favorable considering the long-term service expected from ZLS crowns. Crack formation and propagation might be hindered by the transformation of the tetragonal zirconia phase that is distributed in the glass phase of lithium. ${ }^{25,26}$ Sieper et al ${ }^{26}$ reported the presence of arrest lines that hindered failure, which supports the assumption that microcracks have a smaller effect on fracture strength in comparison to conventional lithium disilicate ceramics.

A limitation to that study was that $\mu \mathrm{CT}$ was carried out prior to cementation. This was done to better visualize the gap distance. However, this test condition may not fully simulate the clinical situation as the cement could alter the value of the gap between the prepared abutments and the crowns.

\section{Conclusion}

The increase in TOC from $12^{\circ}$ and $20^{\circ}$ did not affect the marginal and internal adaptation of ZLS crowns. Increased finish line curvature on the buccal compared to the other surfaces seemed to increase gap distance. CL simulating 1 year service did not result in any fractures. A TOC of $20^{\circ}$ resulted in higher values of load to fracture. Clinically, more realistic and applicable preparations of $20^{\circ} \mathrm{TOC}$ for all ceramic ZLS full coverage crowns will result in acceptable gap distance and load to fracture values.

\section{Disclosure}

The authors report no conflicts of interest in this work.

\section{References}

1. Miyazaki T, Hotta Y, Kunii J, Kuriyama S, Tamaki Y. A review of dental $\mathrm{CAD} / \mathrm{CAM}$ : current status and future perspectives from 20 years of experience. Dent Mater J. 2009;28(1):44-56.

2. Kern M, Thompson VP, Beuer F, et al. All-Ceramics at a Glance. 3rd ed. Arbeitsgemeinschaft für Keramik in der Zahnheilkunde e.V., Ettlingen; 2017.

3. Conrad HJ, Seong WJ, Pesun IJ. Current ceramic materials and systems with clinical recommendations: a systematic review. J Prosthet Dent. 2007;98(5):389-404.

4. Gardner FM. Margins of complete crowns--literature review. J Prosthet Dent. 1982;48(4):396-400.

5. Yeo I-S, Yang J-H, Lee J-B. In vitro marginal fit of three all-ceramic crown systems. J Prosthet Dent. 2003;90(5):459-464. 
6. Anusavice KJ, Carroll JE. Effect of incompatibility stress on the fit of metal-ceramic crowns. J Dent Res. 1987;66(8):1341-1345.

7. Karlsson S. A clinical evaluation of fixed bridges, 10 years following insertion. J Oral Rehabil. 1986;13(5):423-432.

8. Bergenholtz G, Cox CF, Loesche WJ, Syed SA. Bacterial leakage around dental restorations: its effect on the dental pulp. J Oral Pathol. 1982;11(6):439-450.

9. Rossetti PHO, Valle Aldo, Carvalho Rmde, Goes MFD, Pegoraro LF, do Valle AL, de Goes MF. Correlation between margin fit and microleakage in complete crowns cemented with three luting agents. J Appl Oral Sci. 2008;16(1):64-69.

10. Boitelle P, Mawussi B, Tapie L, Fromentin O. A systematic review of CAD/ CAM fit restoration evaluations. J Oral Rehabil. 2014;41(11):853-874.

11. Papadiochou S, Pissiotis AL. Marginal adaptation and CAD-CAM technology: A systematic review of restorative material and fabrication techniques. J Prosthet Dent. 2018;119(4):545-551.

12. Mclean JW, von F. The estimation of cement film thickness by an in vivo technique. Br Dent J. 1971;131(3):107-111.

13. Contrepois M, Soenen A, Bartala M, Laviole O. Marginal adaptation of ceramic crowns: a systematic review. J Prosthet Dent. 2013;110(6): 447-454.

14. Yildirim G, Uzun IH, Keles A. Evaluation of marginal and internal adaptation of hybrid and nanoceramic systems with microcomputed tomography: an in vitro study. J Prosthet Dent. 2017;118(2):200-207.

15. Groten M, Axmann D, Pröbster L, Weber H. Determination of the minimum number of marginal gap measurements required for practical in vitro testing. $J$ Prosthet Dent. 2000;83(1):40-49.

16. Praça L, Pekam FC, Rego RO, Radermacher K, Wolfart S, Marotti J. Accuracy of single crowns fabricated from ultrasound digital impressions. Dent Mater. 2018;34(11), :e280-e288.

17. Pelekanos S, Koumanou M, Koutayas SO, Zinelis S, Eliades G. Micro$\mathrm{CT}$ evaluation of the marginal fit of different In-Ceram alumina copings. Eur J Esthet Dent. 2009;4(3):278-292.

18. Seo D, Yi Y, Roh B. The effect of preparation designs on the marginal and internal gaps in Cerec3 partial ceramic crowns. $J$ Dent. 2009;37(5):374-382.

19. Borba M, Cesar PF, Griggs JA, Della Bona Álvaro. Adaptation of allceramic fixed partial dentures. Dent Mater. 2011;27(11):1119-1126.

20. Wagner WC, Chu TM. Biaxial flexural strength and indentation fracture toughness of three new dental core ceramics. J Prosthet Dent. 1996;76(2):140-144.

21. Elsaka SE, Elnaghy AM. Mechanical properties of zirconia reinforced lithium silicate glass-ceramic. Dent Mater. 2016;32(7):908-914.

22. Swain MV, Coldea A, Bilkhair A, Guess PC. Interpenetrating network ceramic-resin composite dental restorative materials. Dent Mater. 2016;32(1):34-42.

23. VITA SUPRINITY ${ }^{\circledR}$. Technical and Scientific Documentation. Germany: Vita Zahnfabrik, Bad Säckingen; 2014.

24. Gracis S, Thompson V, Ferencz J, Silva N, Bonfante E. A new classification system for all-ceramic and ceramic-like restorative materials. Int J Prosthodont. 2016;28(3):227-235.

25. Manicone PF, Rossi Iommetti P, Raffaelli L. An overview of zirconia ceramics: basic properties and clinical applications. J Dent. 2007;35(11):819-826.

26. Sieper K, Wille S, Kern M. Fracture strength of lithium disilicate crowns compared to polymer-infiltrated ceramic-network and zirconia reinforced lithium silicate crowns. J Mech Behav Biomed Mater. 2017;74:342-348.

27. Winkelmeyer C, Wolfart S, Marotti J. Analysis of tooth preparations for zirconia-based crowns and fixed dental prostheses using stereolithography data sets. J Prosthet Dent. 2016;116(5):783-789.

28. Wilson $\mathrm{AH}, \mathrm{Chan} \mathrm{DCN}$. The relationship between preparation convergence and retention of extracoronal retainers. J Prosthodont. 1994;3(2):74-78.

29. Goodacre CJ, Campagni WV, Aquilino SA. Tooth preparations for complete crowns: An art form based on scientific principles. J Prosthet Dent. 2001;85(4):363-376.

30. Ayad MF, Maghrabi AA, Rosenstiel SF. Assessment of convergence angles of tooth preparations for complete crowns among dental students. J Dent. 2005;33(8):633-638.
31. Bowley JF, Kieser J. Axial-wall inclination angle and vertical height interactions in molar full crown preparations. J Dent. 2007;35(2):117-123.

32. Corazza PH, Feitosa SA, Borges AL, Della Bona A. Influence of convergence angle of tooth preparation on the fracture resistance of Y-TZPbased all-ceramic restorations. Dent Mater. 2013;29(3):339-347.

33. Tiu J, Al-Amleh B, Waddell JN, Duncan WJ. Clinical tooth preparations and associated measuring methods: a systematic review. J Prosthet Dent. 2015;113(3):175-184

34. Shillingburg HT, Hobo S, Whitsett LD, Jacobi R, Brackett SE. Fundamentals of Fixed Prosthodontics. Tokyo: Quintessence; 2007.

35. Beuer F, Edelhoff D, Gernet W, Naumann M. Effect of preparation angles on the precision of zirconia crown copings fabricated by CAD/ CAM system. Dent Mater J. 2008;27(6):814-820.

36. Groten M, Girthofer S, Probster L. Marginal fit consistency of copymilled all-ceramic crowns during fabrication by light and scanning electron microscopic analysis in vitro. J Oral Rehabil. 1997;24(12):871-881.

37. Hmaidouch R, Neumann P, Mueller WD. Influence of preparation form, luting space setting and cement type on the marginal and internal fit of CAD/CAM crown copings. Int J Comput Dent. 2011;14:219-226.

38. Asavapanumas $\mathrm{C}$, Leevailoj $\mathrm{C}$. The influence of finish line curvature on the marginal gap width of ceramic copings. $J$ Prosthet Dent. 2013;109(4):227-233.

39. Nakamura T, Dei N, Kojima T, Wakabayashi K. Marginal and internal fit of Cerec $3 \mathrm{CAD} / \mathrm{CAM}$ all-ceramic crowns. Int J Prosthodont. 2003; 16:244-248.

40. Nakamura T, Tanaka H, Kinuta S, et al. In Vitro Study on Marginal and Internal Fit of CAD/CAM All-ceramic Crowns. Dent Mater J. 2005;24(3):456-459.

41. Beuer F, Aggstaller H, Richter J, Edelhoff D, Gernet W. Influence of preparation angle on marginal and internal fit of CAD/CAM-fabricated zirconia crown copings. Quintessence Int. 2009;40:243-250.

42. Castillo Oyagüe R, Sánchez-Jorge MI, Sánchez Turrión A. Influence of $\mathrm{CAD} / \mathrm{CAM}$ scanning method and tooth-preparation design on the vertical misfit of zirconia crown copings. Am J Dent. 2010;23(6):341-346.

43. Wiskott HW, Nicholas JL, Belser UC. Stress fatigue: basic principles and prosthodontic implications. Int J Prosthodont. 1995;8(2): $105-116$.

44. Waltimo A, Könönen M. A novel bite force recorder and maximal isometric bite force values for healthy young adults. Eur J Oral Sci. 1993;101(3):171-175.

45. Preis V, Behr M, Hahnel S, Rosentritt M. Influence of cementation on in vitro performance, marginal adaptation and fracture resistance of CAD/CAM-fabricated ZLS molar crowns. Dent Mater. 2015;31(11):1363-1369.

46. Monteiro JB, Oliani MG, Guilardi LF, et al. Fatigue failure load of zirconia-reinforced lithium silicate glass ceramic cemented to a dentin analogue: Effect of etching time and hydrofluoric acid concentration. J Mech Behav Biomed Mater. 2018;77:375-382.

47. De Jager N, Pallav P, Feilzer AJ. The influence of design parameters on the FEA-determined stress distribution in CAD-CAM produced all-ceramic dental crowns. Dent Mater. 2005;21(3):242-251.

48. Rosentritt M, Steiger D, Behr M, Handel G, Kolbeck C. Influence of substructure design and spacer settings on the in vitro performance of molar zirconia crowns. J Dent. 2009;37(12):978-983.

49. Bonfante EA, Rafferty B, Zavanelli RA, et al. Thermal/mechanical simulation and laboratory fatigue testing of an alternative yttria tetragonal zirconia polycrystal core-veneer all-ceramic layered crown design. Eur J Oral Sci. 2010;118(2):202-209.

50. Assuncao SRO, Ozcan M, Augusto PC, et al. Marginal and internal discrepancies related to margin design of ceramic crowns fabricated by a CAD/CAM System. J Prosthodont. 2012;21:94-100.

51. Komine F, Iwai T, Kobayashi K, Matsumura H. Marginal and internal adaptation of zirconium dioxide ceramic copings and crowns with different finish line designs. Dent Mater J. 2007;26(5):659-664.

52. Yoon SS, Cheong C, Preisser J, Jun S, Chang BM, Wright RF. Measurement of total occlusal convergence of 3 different tooth preparations in 4 different planes by dental students. $J$ Prosthet Dent. 2014;112(2):285-292. 


\section{Publish your work in this journal}

Clinical, Cosmetic and Investigational Dentistry is an international, peer-reviewed, open access, online journal focusing on the latest clinical and experimental research in dentistry with specific emphasis on cosmetic interventions. Innovative developments in dental materials, techniques and devices that improve outcomes and patient satisfac- tion and preference will be highlighted. The manuscript management system is completely online and includes a very quick and fair peerreview system, which is all easy to use. Visit http://www.dovepress. com/testimonials.php to read real quotes from published authors.

Submit your manuscript here: https://www.dovepress.com/clinical-cosmetic-and-investigational-dentistry-journal 